\title{
PENATALAKSANAAN FISIOTERAPI UNTUK MENURUNKAN TEKANAN DARAH PADA LANSIA YANG MENGALAMI HIPERTENSI DENGAN METODE SLOW DEEP BREATHING DAN SWEDISH MASSAGE THERAPY DI DESA A. YANI PURA
}

\section{Management of Physiotherapy to Reduce Blood Pressure in Elderly Hypertension utilize Slow Deep Breathing and Swedish Massage Methode Therapy in A. Yani Pura Village}

\author{
Aniesa Nur Laily Pertiwi ${ }^{1}$, Yulisha Eva Oktaviani ${ }^{2}$, Nafi'ah $^{2 *}$ \\ ${ }^{1}$ Mahasiswa Program Studi DIII Fisioterapi Politeknik Unggulan Kalimantan \\ ${ }^{2}$ Dosen Program Studi DIII Fisioterapi Politeknik Unggulan Kalimantan \\ ${ }^{*}$ Corresponding Author Email: nafiah@polanka.ac.id
}

\begin{abstract}
Hypertension is a condition where blood pressure continues to increase in a person who exceeds $120 / 80 \mathrm{mmHg}$ with a long period of time even though the person is in a state of rest. The purpose of this research is to know physiotherapy management in the elderly who have hypertension and whether decrease in blood pressure after a physiotherapy intervention in the form of slow deep breathing (SDB) and swedish massage therapy (SMT). This study uses case study method using a single sample of hypertensive patients. Treatment is 12 times in 4 weeks time, measured using sphygmomanometer. The results of the research obtained after the evaluation is a decrease in blood pressure in hypertensive conditions. Based on this, SDB and SMT are effectively used in lowering blood pressure in hypertensive conditions. Recommended to future researchers be able to use shorter doses and carry out routine blood pressure checks.
\end{abstract}

Keywords : hypertension, elderly, slow deep breathing, swedish massage therapy

\section{ABSTRAK}

Hipertensi merupakan kondisi tekanan darah yang terus meningkat melebihi 120/80 $\mathrm{mmHg}$ dengan selang waktu yang lama walaupun orang tersebut dalam keadaan istirahat. Tujuan penelitian ini adalah untuk mengetahui penatalaksanaan fisioterapi pada lansia yang mengalami hipertensi dan apakah ada penurunan tekanan darah setelah diberikan intervensi fisioterapi berupa slow deep breathing (SDB) dan swedish massage therapy (SMT). Penelitian ini menggunakan metode case study dengan menggunakan satu sampel pasien hipertensi. Treatment dilakukan sebanyak 12 kali dalam kurun waktu 4 minggu yang diukur sphygmomanometer. Hasil penelitian yang didapatkan setelah dilakukan evaluasi yaitu adanya penurunan tekanan darah pada kondisi hipertensi. Berdasarkan hal tersebut, SDB dan SMT efektif digunakan dalam menurunkan tekanan darah pada kondisi hipertensi. Disarankan kepada peneliti selanjutnya agar dapat menggunakan dosis yang lebih singkat dan melakukan pemeriksaan tekanan darah secara rutin.

Kata kunci : hipertensi, lansia, slow deep breathing, swedish massage therapy 


\section{PENDAHULUAN}

Kemajuan ekonomi, pengetahuan, dan teknologi terutama pada ilmu kesehatan dan pelayanan kesehatan mengakibatkan meningkatnya usia harapan hidup manusia. Hal ini akan mengakibatkan bertambahnya jumlah orang lanjut usia (lansia) (Sari et al., 2019). Permasalahan-permasalahan yang perlu perhatian khusus untuk lansia, akan menimbulkan perubahan fisik, kognitif, perasaan, sosial, dan seksual. Salah satu perubahan yang terjadi pada lansia yakni perubahan pada sistem kardiovaskuler seperti hipertensi (Adam, 2019). Hipertensi merupakan sebuah kondisi dimana tekanan darah meningkat diatas normal yaitu $140 / 90 \mathrm{mmHg}$ dan dapat mengalami resiko kesakitan (morbiditas) bahkan kematian (mortalitas). Penyakit ini sering dikatakan sebagai the silent killer (pembunuh diam-diam) (Agustina et al., 2016).

World Health Organization (WHO) mencatat pada tahun 2013 sedikitnya terdapat 972 juta kasus hipertensi dan diperkirakan akan meningkat menjadi 1,15 milyar kasus pada tahun 2025 atau sekitar $29 \%$ dari total penduduk di dunia menderita hipertensi, dimana 333 juta berada di negara maju dan 639 juta sisanya berada di negara berkembang termasuk di Indonesia (Yulianti, 2019). Menurut Riskesdas (2018), menunjukkan angka prevalensi hipertensi hasil pengukuran mencapai 34,1\% meningkat tajam dari 25,8\% pada tahun 2013, dengan angka prevalensi tertinggi di Provinsi Kalimantan Selatan sebesar $44,1 \%$ dan terendah di provinsi Papua sebesar 22,2\%. Banyaknya jumlah penderita hipertensi di Kalimantan Selatan dengan jumlah 10.162 orang dalam tahun 2018 dan permasalahan yang ditimbulkan akibat dari hipertensi seperti nyeri pada kepala bagian oksipital saat bangun pagi, sering merasa kelelahan, penglihatan kabur, dan merasa pusing, menyebabkan berbagai pengobatan terus dikembangkan termasuk pengobatan non farmakologis diantaranya meliputi swedish massage therapy dan slow deep breathing (Ananto, 2018).

Swedish Massage Therapy merupakan manipulasi dari jaringan tubuh untuk mempersingkat waktu pemulihan dari ketegangan otot tanpa meningkatkan beban kerja jantung (Hermawan, 2015). Menurut penelitian yang dilakukan oleh Intarti (2018) penerapan Swedish Massage Therapy (SMT) pada wanita lansia efektif sebagai upaya penatalaksanaan hipertensi di posyandu lansia tanpa efek samping yang merugikan. Hal tersebut juga didukung dengan penelitian yang dilakukan oleh Adawiyah \& Fithriani (2017), yang menunjukkan bahwa Swedish Massage Therapy (SMT) berpengaruh terhadap perubahan tekanan darah pada pasien lansia dengan hipertensi di Balai Sosial Lanjut Usia Mandalika NTB.

Selain Swedish Massage Therapy (SMT), terdapat Manuver Slow Deep Breathing (SDB) yang merupakan tindakan non farmakologis pada pasien hipertensi yang dapat membantu dalam menurunkan tekanan darah. Manuver ini memiliki sistem yang meningkatkan sensitivitas baroreflek arteri, kemudian hal ini akan menimbulkan peningkatan firing rate dari baroreseptor sehingga berdampak pada beberapa faktor, diantaranya menurunkan impuls saraf simpatik dan membuat pembuluh darah perifer menjadi vasodilatasi yang kemudian dapat menurunkan tekanan darah (Wiharja et al., 2016). Penelitian ini didukung oleh Rasyidah (2018), yang menyatakan bahwa ada pengaruh slow deep breathing terhadap penurunan tekanan darah sistolik pada penderita hipertensi, sementara tekanan diastolik juga terjadi penurunan tetapi tidak terlalu signifikan. Hal tersebut juga didukung dengan penelitian yang dilakukan oleh Siswanti \& Purnomo (2018). 
Menurut penelitian pendahuluan yang telah saya lakukan terhadap 60 responden, didapatkan bahwa 94,9\% orang mengalami hipertensi dan 64,4\% diantaranya mengkonsumsi obat pengencer darah, namun tidak ditemukan penderita yang menggunakan slow deep breathing dan swedish massage therapy sebagai intervensi dalam menurunkan hipertensi. Selain itu, belum ada penelitian penggunaan slow deep breathing dan swedish massage therapy sebagai intervensi dalam menurunkan hipertensi di Kalimantan Selatan. Oleh karena itu, maka peneliti tertarik untuk melakukan penatalaksanaan fisioterapi dengan memberikan metode slow deep breathing dan swedish massage therapy pada pasien hipertensi guna membantu menurunkan tekanan darah di Desa Desa A. Yani Pura, Kelurahan Binuang, Kecamatan Binuang, Kabupaten Tapin, Provinsi Kalimantan Selatan.

\section{METODE PENELITIAN}

\section{A. Jenis Penelitian}

Jenis penelitian merupakan penelitian studi kasus (case study), yaitu penelitian yang mencakup pengkajian satu unit penelitian secara intensif, misalnya satu pasien, keluarga, kelompok, komunitas, atau institusi. Karakteristik studi kasus adalah subjek yang diteliti sedikit tetapi aspek-aspek yang diteliti banyak.

B. Tempat dan Waktu Penelitian

Waktu penelitian dimulai pada bulan Maret - April 2020. Adapun Tempat Penelitian ini dilaksanakan di Transad Blok F. Jl. Flores No 27, RT. 06 RW. 02 , Desa A.Yani Pura, Kelurahan Binuang, Kecamatan Binuang, Kabupaten Tapin, Provinsi Kalimantan Selatan.

\section{Prosedur Pengambilan Data}

1. Data primer diperoleh dengan melakukan pemeriksaan dan pengukuran fisioterapi pada pasien yang dijadikan sampel khusus.

2. Data sekunder diperoleh dengan melihat hasil laboratorium dan data prevalensi hipertensi.

D. Instrumen Penelitian

1. Alat ukur vital sign (tensimeter, thermometer, stetoskop) digunakan dengan tujuan untuk mengukur dan mengetahui tanda-tanda vital pada pasien.

2. Alat tulis digunakan dengan tujuan sebagai alat pendukung dalam penelitian.

\section{E. Alur Penelitian}

1. Membuat surat izin penelitian di Prodi DIII Fisioterapi Politeknik Unggulan Kalimantan

2. Mengurus surat izin penelitian di Desa A. Yani Pura

3. Mencari sampel penelitian terkait kasus Hipertensi yang memiliki kriteria tidak meminum obat pengencer darah, memiliki riwayat asma, dan jantung

4. Melakukan pemeriksaan vital sign

5. Memberikan intervensi fisioterapi berupa Slow Deep Breathing dan Swedish Massage Therapy

6. Melakukan evaluasi hasil pemberian intervensi fisioterapi

\section{F. Pengolahan dan Analisa Data}

1. Pengolahan Data

\section{a. Editing}

Secara umum editing merupakan kegiatan untuk pengecekan dan perbaikan isi formulir atau kuesioner yang telah di isi. Dalam penelitian ini yang dilakukan oleh peneliti adalah memeriksa kembali data responden yang diperoleh atau dikumpulkan. Kemudian editing dilakukan pada tahap pengumpulan data atau setelah data terkumpul (Lestari, 2018). 
b. Tabulasi Data

Tabulasi data atau memasukkan data merupakan kegiatan dalam penelitian kemudian dimasukkan ke dalam tabel, baik tabel untuk data mentah maupun tabel kerja untuk melihat hasil evaluasi penatalaksanaan fisioterapi untuk menurunkan tekanan darah pada penderita hipertensi.

2. Analisa Data

Data yang diambil untuk menurunkan tekanan darah pada kondisi Hipertensi adalah dengan menggunakan vital sign tekanan darah. Modalitas fisioterapi yang diberikan berupa Slow Deep Breathing dan Swedish Massage Therapy. Intervensi dilakukan selama 4 minggu, dengan 3 kali pertemuan dalam 1 minggu. Intervensi slow deep bretahing dilakukan selama 10 menit, sedangkan swedish massage therapy dilakukan selama 15 menit sekali pertemuan. Lalu data dianalisis melalui evaluasi selama 12 kali dalam 1 bulan penelitian. Dari data tersebut dapat dilihat bagaimana pengaruh pemberian modalitas fisioterapi tersebut pada kasus Hipertensi untuk menurunkan tekanan darah apakah mengalami penurunan atau bahkan tidak terjadi perubahan sama sekali.

\section{G. Etika Penelitian}

1. Mengajukan Informed consent

Persetujuan penelitian (informed consent) diberikan dalam bentuk lembar persetujuan penelitian. Bagi sampel penelitian yang setuju berpartisipasi dalam penelitian dimohon untuk menandatangani lembar persetujuan penelitian. Sebelumnya sampel penelitian diberikan informasi tentang tujuan penelitian, sifat keikutsertaan, dan dampak yang timbul sebagai akibat berpartisipasi dalam penelitian ini (Sakwati, 2012)

2. Anonymity (Tanpa Nama)

Untuk menjaga kerahasiaan responden, maka peneliti tidak akan mencantumkan nama responden pada lembar pengumpulan data. Cukup dengan memberi nomor kode atau tanda pada masing-masing lembar tersebut (Lestari, 2018).

3. Confidentiality (Kerahasiaan)

Masalah ini merupakan masalah etika dengan memberikan jaminan kerahasiaan hasil penelitian, baik informasi maupun masalah-masalah lainnya. Semua informasi yang telah dikumpulkan dijamin kerahasiaannya oleh peneliti, hanya kelompok data tertentu yang akan dilaporkan pada hasil riset (Gustini, 2015).

\section{HASIL DAN PEMBAHASAN}

\section{A. Hasil}

Pasien atas nama Ny. S usia 53 tahun dengan diagnosis hipertensi. Sekitar \pm 2 tahun yang lalu pasien mengeluhkan nyeri dan kaku pada kepala bagian belakang hingga leher disertai jantung berdebar-debar. Setiap 2 - 3 kali dalam seminggu pasien sering melakukan pemeriksaan tekanan darah di rumahnya. Pasien merasakan tekanan darah tinggi ketika pasien selesai melakukan aktivitas seperti mengerjakan tugas-tugas sekolahnya sehingga pasien kurang tidur dan merasakan stress. Saat ini pasien sudah tidak mengkonsumsi obat captopril $25 \mathrm{mg}$ sejak bulan November tahun 2019. 
Setelah dilakukan assessment fisioterapi serta pengukuran menggunakan sphygmomanometer untuk mengukur tekanan darah pasien. Hasil dari pemeriksaan tersebut didapatkan problematik fisioterapi berupa adanya spasme spasme pada $m$. Upper trapezius dan $m$. Sternocleidomastoideus serta nyeri pada gerak ekstensi dan lateral fleksi sinistra pada regio cervical. Dari problematik yang didapatkan pasien maka selanjutnya pasien mendapat penatalaksanaan fisioterapi berupa Slow Deep Breathing (SDB) dan Swedish Massage Therapy (SMT) selama 12 kali berturut turut dalam kurun waktu 4 minggu dari tanggal 03 April hingga 27 April 2020 didapatkan hasil berikut ini:

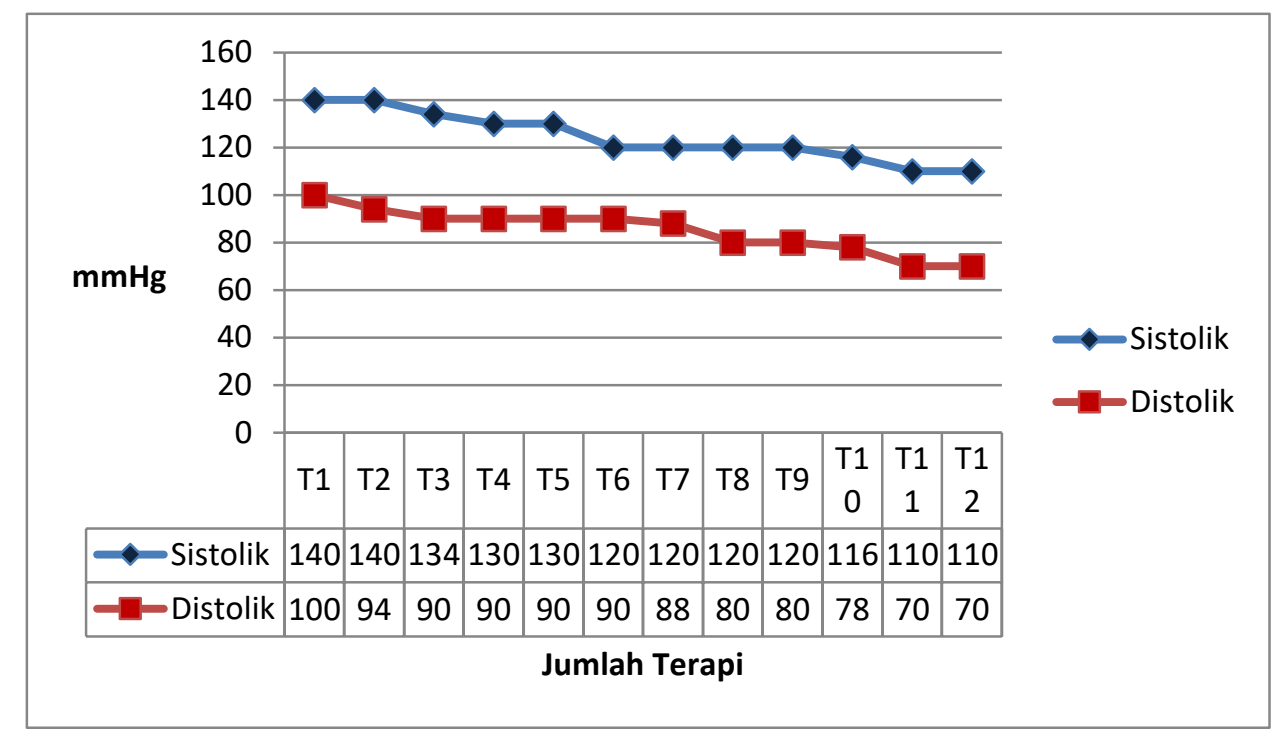

Gambar 1. Hasil Pemeriksaan Menggunakan Sphygmomanometer Setelah Diberikan Intervensi 12 Kali dalam 4 Minggu

Gambar grafik di atas menunjukkan hasil evaluasi terapi pasien dengan menggunakan pengukuran sphygmomanometer. Dari pengukuran sebelum terapi didapatkan nilai 140/100 mmHg. Pada pertemuan pertama, didapatkan hasil belum ada terjadinya penurunan pada tekanan darah sistolik maupun distolik dikarenakan belum adanya adaptasi dari intervensi yang telah dilakukan. Lalu pada pertemuan kedua terjadi penurunan sebesar $6 \mathrm{mmHg}$ pada tekanan darah distolik menjadi 94 $\mathrm{mmHg}$. Pertemuan ketiga terjadi penurunan pada tekanan darah sistolik sebesar 6 $\mathrm{mmHg}$ dan tekanan darah distolik sebesar $4 \mathrm{mmHg}$ sehingga tekanan darah menjadi $134 / 90 \mathrm{mmHg}$. Terjadi penurunan pada pertemuan ke dua dan ke tiga karena pasien mulai merasakan relaksasi dari intervensi yang diberikan. Pasien juga mulai mengontrol gaya hidup,

Selanjutnya pada minggu kedua pada pertemuan ke empat, terjadi penurunan kembali pada tekanan darah sistolik sebesar $10 \mathrm{mmHg}$, sehingga tekanan darah menjadi $130 \mathrm{mmHg}$. Untuk pertemuan ke lima tekanan darah pasien masih berada di angka 130/90 mmHg. Namun pada pertemuan ke enam, terjadi penurunan pada tekanan darah sistolik sebesar $10 \mathrm{mmHg}$, sehingga tekanan darah pasien menjadi $120 / 90 \mathrm{mmHg}$. Untuk pertemuan keempat dan keenam pada minggu kedua terjadi penurunan tekanan darah diakibatkan dari pasien yang rutin melakukan home program dan edukasi yang sebelumnya telah diberikan kepada terapis. Namun untuk pertemuan kelima, 1 jam sebelum dilakukan intervensi, pasien sempat mengkonsumsi kafein. Sehingga tekanan darah pasien tidak mengalami perubahan atau penurunan. 
Adapun pada minggu ke tiga pertemuan ke tujuh didapatkan hasil evaluasi adanya penurunan sebesar $2 \mathrm{mmHg}$ pada tekanan darah distolik. Pada pertemuan ke delapan terjadi penurunan kembali pada tekanan darah diastolik sebesar 2 $\mathrm{mmHg}$. Namun pada pertemuan ke sembilan, tidak terjadi perubahan pada tekanan darah sistolik maupun distolik. Sehingga pada minggu ke tiga didapatkan hasil tekanan darah pasien menjadi 120/80 mmHg. Pada pertemuan ke tujuh dan delapan terjadi penurunan tekanan darah, dikarenakan pasien mulai merasakan tidak adanya gangguan tidur lagi. Namun pada pertemuan ke sembilan pasien mengatakan bahwa merasakan ada sedikit pikiran yang mengganggu. Sehingga tidak terjadi penurunan tekanan darah pada pasien.

Pada minggu ke empat didapatkan hasil evaluasi adanya penurunan pada pertemuan ke sepuluh sebesar $4 \mathrm{mmHg}$ pada tekanan darah sistolik dan $2 \mathrm{mmHg}$ pada tekanan darah distolik. Kemudian pada pertemuan ke sebelas terjadi penurunan kembali pada tekanan darah sistolik sebesar $6 \mathrm{mmHg}$ dan tekanan darah distolik sebesar $8 \mathrm{mmHg}$. Namun pada pertemuan ke dua belas, tidak terjadi perubahan pada tekanan darah sistolik maupun distolik. Sehingga pada minggu terakhir penelitian ini didapatkan hasil tekanan darah pasien menjadi 110/70 mmHg. Pada pertemuan ke sepuluh dan sebelas terjadi penurunan kembali, karena pasien telah melakukan home program dan edukasi yang sebelumnya telah diberikan oleh terapis dengan teratur. Karena aktivitas fisik seperti senam pada usia lanjut, joging ataupun jalan santai yang dilakukan secara rutin akan meningkatkan kebugaran fisik, sehingga secara tidak langsung senam dapat meningkatkan fungsi jantung dan menurunkan tekanan darah serta mengurangi resiko penumpukan lemak pada dinding pembuluh darah sehingga akan menjaga elastisitasnya. Disisi lain akan melatih otot jantung dalam berkontraksi sehingga kemampuan pemompaannya akan selalu terjaga. Selain itu hasil penelitian menggunakan functional neuroimaging menunjukkan bahwa musik dapat memodulasi amigdala. Amigdala merupakan komponen utama sistem limbik yang berperan dalam mengatur emosi. Selanjutnya subdivisi amigdala dan central nucleus memproyeksikan informasi yang diterima ke hipotalamus yang berperan dalam mengatur respons otonom dan hormonal. Hipotalamus yang terstimulasi akan merangsang pengeluaran gelombang otak pada bagian frontal dan parietal korteks serebri. Gelombang yang dihasilkan dari stimulasi musik (relaxing music) adalah gelombang alfa. Gelombang alfa ini menggambarkan tubuh dalam keadaan rileks. Sehingga pasien sudah tidak memiliki gangguan tidur dan pasien tetap menjaga pola hidupnya selama 4 minggu dilakukan penelitian. Namun pada pertemuan terakhir, sebelum dilakukan intervensi pasien mengkonsumsi daging sapi (rawon) saat menghadiri rapat bulanan di lingkungan sekitar pasien.

\section{B. Pembahasan}

Dari hasil penelitian yang telah dijabarkan dapat dilihat bahwa setelah dilakukan evaluasi setiap minggu dalam setiap kali pertemuan dengan menggunakan sphygmomanometer, terjadi penurunan pada tekanan darah sistolik maupun distolik. Sebelumnya tekanan darah pasien berada di nilai $140 / 100 \mathrm{mmHg}$, namun setelah terapi terjadi penurunan tekanan darah menjadi $110 / 70 \mathrm{mmHg}$. Saat ini kondisi pasien terlihat lebih baik dari sebelum dilakukannya penatalaksanaan fisioterapi, pasien juga masih melakukan home program yang telah diberikan terapis. Dengan begitu modalitas fisioterapi berupa slow deep breathing dan swedish massage therapy yang digunakan dalam penatalaksanaan fisioterapi terhadap lansia yang mengalami hipertensi memiliki pengaruh pada penurunan tekanan darah sistolik dan distolik.

Tekanan darah yaitu jumlah gaya yang diberikan oleh darah di bagian dalam arteri saat darah dipompa ke seluruh sistem peredaran darah. Tekanan darah tidak pernah konstan, tekanan darah dapat berubah drastis dalam hitungan detik, 
menyesuaikan diri dengan tuntutan pada saat itu (Benson, 2012). Meningkatnya tekanan darah di dalam arteri bisa terjadi melalui beberapa cara yaitu jantung memompa lebih kuat, sehingga mengalirkan darah pada setiap denyut jantung dipaksa untuk melalui pembuluh yang sempit dari pada biasanya dan menyebabkan naiknya tekanan. Inilah yang terjadi pada usia lanjut, dimana dinding arterinya telah menebal dan kaku karena arteriosklerosis. Kondisi ini menyebabkan tekanan pada pembuluh darah meningkat. Tekanan yang terlalu tinggi dapat merobek pembuluh dan mengakibatkan terjadinya pendarahan atau komplikasi lainnya (Triyanto, 2014).

Slow deep breathing termasuk ke dalam latihan dan relaksasi yang dapat menurunkan tekanan darah karena dapat menurunkan aktivitas saraf simpatis melalui peningkatan central inhibitory rythms yang akan berdampak pada penurunan output simpatis. Penurunan output simpatis akan menurunkan produksi hormone epineprin yang ditangkap oleh reseptor alfa sehingga akan mempengaruhi otot polos dari pembuluh darah sehingga terjadinya vasodilatasi yang akan menurunkan tahanan perifer yang juga menyebabkan tekanan darah menjadi turun. Pada saat relaksasi terjadi perpanjangan serabut otot, menurunnya pengiriman impuls saraf ke otak, menurunnya aktivitas otak, dan fungsi tubuh yang lain, karakteristik dari respon relaksasi ditandai oleh menurunnya denyut nadi, jumlah pernafasan dan penurunan tekanan darah (Septiawan \& Permana, 2018). Hal ini bersesuaian dengan penelitian yang dilakukan oleh Sumartini \& Miranti (2019), bahwa latihan slow deep breathing sebanyak tiga kali dalam kurun waktu 3 minggu, masing-masing 15 menit, kemudian diukur tekanan darahnya (post test) didapatkan nilai signifikansi dengan rata-rata tekanan darah sistolik post test adalah $153 \mathrm{mmHg}$ dan tekanan darah diastolik posttest $96 \mathrm{mmHg}$. Menurut Septiawan et al (2018), slow deep breathing enam sampai sepuluh kali dalam satu menit yang dilakukan selama 21 hari secara rutin didapatkan hasil ada pengaruh terhadap tekanan darah pada penderita hipertensi. Sedangkan menurut Berek (2018), latihan SDB yang dilakukan selama 15 menit dalam waktu 14 hari, terdapat perbedaan yang sangat bermakna pada tekanan darah diastolik sebelum dan setelah mendapat intervensi.

Kemudian pemberian swedish massage therapy yaitu merupakan suatu pijatan untuk membantu mempercepat proses pemulihan dengan menggunakan sentuhan tangan untuk mempersingkat waktu pemulihan dari ketegangan otot (kelelahan), meningkatkan sirkulasi darah tanpa meningkatkan beban kerja jantung dan efektif dalam membantu menurunkan tekanan darah. Teknik pada swedish massage therapy memiliki efek pada sistem saraf otonom yang dapat menyebabkan berbagai hasil pada tanda-tanda vital seperti tekanan darah, nadi dan pernapasan yang akan memunculkan rasa relaksasi yang mempengaruhi kerja saraf otonom mengubah fisiologi dominan simpatis dan meningkatkan hormon parasimpatis serta neurotransmitter seperti DHEA (Dehidroepinandrosteron) dan dopamine atau endorfin. Hormon ini bertindak seperti morphine, bahkan dikatakan 200 kali lebih besar dari morphine. Regulasi sistem parasimpatis ini akhirnya menimbulkan efek ketenangan (Muslimah et al., 2019).

Adapun teknik swedish massage therapy yang digunakan dalam menurunkan tekanan darah adalah effleurage dan stroking. Effleurage dan stroking dilakukan dengan menggunakan seluruh permukaan telapak tangan dan jari-jari yang merupakan gerakan pijat yang paling dasar. Menurut Ananto (2018), effleurage dan stroking dapat memperlancar peredaran darah, cairan getah bening apabila dilakukan dengan tekanan yang lembut akan memberikan efek penenangan dan membantu mengalirkan darah di pembuluh balik (darah veneus) agar cepat kembali ke jantung. Oleh karena itu gerakan effelurage dilakukan selalu menuju arah jantung yang merupakan pusat peredaran darah. Efek penurunan tekanan darah dari teknik ini adalah didapatkan melalui peningkatan vasodilatasi pembuluh darah dan getah bening, meningkatkan level serotonin, mengurangi sekresi hormon katekolamin dan 
dapat mengurangi rasa nyeri kepala akibat hipertensi, sehingga komplikasi lebih lanjut dapat dicegah. Hal ini sejalan dengan penelitian yang dilakukan oleh Sukmawati et al (2018), yang menunjukkan bahwa swedish massage therapy efektif untuk menurunkan tekanan darah pada penderita hipertensi. Menurut Shanmugam et al (2017), swedish massage therapy yang dilakukan selama 4 minggu dengan waktu 20 menit menimbulkan penurunan tekanan darah sistolik dan distolik yang signifikan dan menunjukkan bahwa swedish massage therapy adalah metode nonfarmakologis yang efektif daalam menurunkan tekanan darah. Kemudian menurut Ritanti \& Sari (2020), swedish massage merupakan bentuk intervensi yang berfungsi menurunkan tekanan darah guna mencegah terjadinya komplikasi lebih lanjut yang dilakukan selama 20-30 menit untuk satu kali pertemuan, dengan frekuensi pertemuan 3 kali dalam seminggu.

Berdasarkan hal tersebut diketahui bahwa intervensi slow deep breathing yang dilakukan oleh peneliti dengan intensitas 12 kali pengulangan selama 4 minggu dengan waktu 10 menit dan pemberian intervensi swedish massage therapy dengan waktu 15 menit dengan frekuensi pertemuan 3 kali dalam seminggu memberikan penurunanan tekanan darah sistolik dan diastolik sebesar $4-10 \mathrm{mmHg}$ dengan menggunakan alat ukur sphygmomanometer, dimana terjadi penurunan saat dilakukan inetrevensi selama 4 minggu. Selain dapat menurunakan tekanan darah juga disertai dengan penurunan nyeri, baik nyeri tekan maupun nyeri gerak dengan penurunan nyeri sebesar 11 hingga $33 \mathrm{~mm}$ dengan menggunakan alat ukur VAS juga terjadi penurunan 3 skor pada tingkat kecemasan dengan menggunakan alat ukur HARS. Kelebihan melaksanakan treatment ini kepada pasien yaitu setelah dilakukan intervensi ini pasien merasakan rileks. Sehingga yang sebelumnya pasien sering merasakan kecemasan dan gangguan tidur, selama diberikan intervensi ini pasien mulai tidak merasakan gangguan tidur dan mengurangi rasa kecemasan pada pasien lagi. Selain itu juga, treatment ini tidak memerlukan biaya yang besar, tempat yang luas, dan juga waktu yang lama, sehingga intervensi ini dapat lebih efektif dari intervensi yang lainnya. Saat melakukan intervensi ini, peneliti tidak memiliki kendala apapun dalam melaksanakan intervensi tersebut.

\section{KESIMPULAN}

Berdasarkan hasil pemeriksaan yang dilakukan maka diagnosa fisioterapi yang ditegakkan adalah adanya vasokontriksi pembuluh darah dan penurunan VO2 max akibat dari penurunan elastisitas pembuluh darah arteri yang disebabkan oleh hipertensi sejak \pm 2 tahun yang lalu. Sehingga didapatkan hasil pemeriksaan dan diagnosa fisioterapi pada kasus hipertensi yaitu adanya penurunan elastisitas pembuluh darah arteri, penurunan VO2 max, vasokontriksi pada pembuluh darah arteri serta adanya spasme pada $m$. Upper trapezius dekstra dan $m$. Sternocleidomastoideus dekstra dan nyeri pada gerak fleksi, lateral fleksi sinistra dan rotasi sinistra pada regio cervical. Intervensi fisioterapi yang diberikan pada pasien lansia yang mengalami hipertensi untuk menurunkan tekanan darah yaitu slow deep berathing dan swedish massage therapy. Pada penelitian ini didapatkan hasil adanya penurunan pada tekanan darah yang diukur menggunakan sphygmomanometer. 


\section{DAFTAR PUSTAKA}

Agustina, S. M., Sari, S., \& Reni., S. (2016). Faktor-faktor yang Berhubungan dengan Hipertensi pada Lansia di Atas Umur 65 Tahun. Hunter-Gatherers in a Changing World. Pekanbaru: Jurnal Kesehatan Komunitas. 2(01), 41-58.

Ananto, D. P. (2018). Pengaruh Massage Teknik Effleurage Terhadap Tekanan Darah Pada Penderita Hipertensi Di Desa Kalirejo Kabupaten Purworejo. Skripsi. Yogyakarta: Universitas Negeri Yogyakarta. 1-7.

Benson \& Herbert (2012). Menurunkan Tekanan Darah. Buku. Gramedia: Jakarta

Berek, P. A. L. (2018). Pengaruh Slow Deep Breathing dan Pengaturan Natrium Terhadap Penurunan Tekanan Darah Pasien Hipertensi Primer. Prosiding Sintesa LP2M Undhira Bali, 2(11), 499-508.

Gustini, K. (2015). Gambaran Pengetahuan Siswa Siswi Kelas Xi Tentang Penyakit Menular Seksual Di Sma Negeri 24 Bandung. Skripsi. Bandung: Universitas Pendidikan Indonesia.

Hermawan, S. (2015). Perbandingan Pengaruh Sport Massage dan Swedish Massage Terhadap Perubahan Denyut Nadi dan Frekuensi Pernafasan. Skripsi. Yogyakarta: Universitas Negeri Yogyakarta.

Lestari, E. P. (2018). Hubungan Pengetahuan Tentang Bahaya dengan Perilaku Mengkonsumsi Miras pada Remaja di Desa Glagahagung Kecamatan Purwoharjo Kabupaten Banyuwangi. Skripsi. Malang: Universitas Muhammadiyah Malang. 68-83.

Muslimah, N., Awaludin, S., \& Kurniawan, A. (2019). Implementasi Terapi Pijat Swedia Untuk Menurunkan Tingkat Kecemasan dan Menstabilkan Tanda-tanda Vital pada Pasien di Ruang Intensive Care Unit (ICU) Rumah Sakit Prof. Dr. Margono Soekarjo: Case Study. 21(June 2016), Purwokerto: Journal of Bionursing. 668676. https://doi.org/10.3760/cma.j.issn.1674-845X.2019.09.005

Rasyidah, A. Z., (2018). Pengaruh Slow Deep Breathing Terhadap Tekanan Darah pada Penderita Hipertensi di Puskesmas Simpang IV Sipin Kota Jambi. Jambi: Riset Informasi Kesehatan. 7(2), 0-4.

Riset Kesehatan Dasar. (2018). Hasil Utama Riskesdas 2018. Kementrian Kesehatan RI. Badan Penelitian dan Pengembangan Kesehatan. Jakarta: Kementerian Kesehatan Republik Indonesia.

Riset Kesehatan Dasar. (2019). Laporan Riskesdes Nasional Tahun 2018. Kementrian Kesehatan Republik Indonesia. Badan Penelitian dan Pengembangan Kesehatan. Jakarta: Lembaga Penerbit Badan Penelitian dan Pengembangan Kesehatan. (pp. 152).

Ritanti, \& Sari, D. A. (2020). Swedish Massage Sebagai Intervensi Keperawatan Inovasi dalam Menurunkan Tekanan Darah pada Lansia Hipertensi. Skripsi, 5, 54-61. 
Robiatul, A., Dina, F., Nina, F. (2017). Pengaruh Terapi Pijat Swedia Terhadap Perubahan Tekanan Darah pada Pasien Lansia denga Hipertensi di Balai Sosial Lanjut Usia "Mandalika” NTB. Skripsi. Mataram: STIKES Mataram. 3(1), 40-50.

Sakwati, M. (2012). Pengolahan Data (Editing, Coding, Entry, dan Tabulating). 24-34. Skripsi. Malang: Universitas Muhammadiyah Malang.

Sari, L. T., Tinggi, S., Kesehatan, I., \& Husada, P. (2019). Pengaruh Acuyoga Terhadap Penurunan Hipertensi pada Lansia. Sekolah Tinggi Ilmu Kesehatan Patria Husada Blitar: Jurnal Penelitian Kesehatan. 6(2), 69-77.

Septiawan, T., Permana, I., \& Yuniarti, F. A. (2018). Pengaruh Latihan Slow Deep Breathing Terhadap Nilai Tekanan Darah pada Pasien Hipertensi. Tesis, 111-118.

Setyonto, W. (2017). Hubungan Aktivitas Fisik Dengan Kejadian Hipertensi Pada Lansia. Skripsi. Jombang: STIKES Insan Medika Cendekia. 6, 21.

Shanmugam, A., Grace Leni, H., \& Gowri, M. (2017). Effectiveness of Swedish Massage Therapy on Blood Pressure Among Patients with Hypertension at Saveetha Medical Collage Hospital. International Journal of Development Research, 07(07), 14133-14136.

Soleha, T. U., \& Sari, M. I. (2016). Buku Panduan Clinical Skill Laboratory Semester 1 Edisiki ke-3. Buku, 3, 50-65.

Suminar, R. R., Widyo, I. N., Ani. I. (2013). Angka Kematian Operasi Jantung RSUP Dr. Kariadi Semarang Periode Januari 2011 - Januari 2013. Skripsi. Surakarta: Universitas Muhammadiyah Surakarta. 8-48.

Sumartini, N. P., \& Miranti, I. (2019). Pengaruh Slow Deep Breathing Terhadap Tekanan Darah Lansia Hipertensi di Puskesmas Ubung Lombok Tengah. 1. Skripsi. (1), 3849.

Sinurat, L. R., Wijayanti, C. D., \& Adyatmaka, A. (2019). Pengaruh Swedish Massage Terhadap Perubahan Tekanan Darah, Heart Rate dan Tingkat Stress di Puskesmas Helvetia Medan. Skripsi. Medan: Universitas Sari Mutiara Indonesia. 8, 71-87.

Siswanti, H., \& Purnomo, M. (2018). Slow Deep Breathing Terhadap Perubahan Tekanan Darahpada Pasien Hipertensi. Universitas Muhammadiyah Purwokerto: The 8th University Research Colloquium 2018. 8, 198-204.

Sukmawati. (2016). Faktor - faktor yang Berhubungan dengan Kejadian Hipertensi Stadium 1 dan Stadium 2 pada Lansia Desa Borimatangkasa Dusun Bontosunggu Kec. Bajeng Barat. Skripsi. Makassar: UIN Alauddin Makassar. 18-19.

Sukmawati, A. S., Pebriani, E., \& Setiawan, A. A. (2018). Kecemasan Lansia Di Balai Pelayanan Sosial Tresna Wredha (Bpstw ) Unit Budi Luhur Yogyakarta (Swedish Massage Therapy Reduce The Anxiety Level Among Older People At the Nursing home of Social Service Center (BPSTW) Unit Budi Luhur Yogyakarta). Skripsi. Yogyakarta: Universitas Jenderal Achmad Yani Yogyakarta. 5(2), 117-122. 
Sumartini, N. P., \& Miranti, I. (2019). Pengaruh Slow Deep Breathing Terhadap Tekanan Darah Lansia Hipertensi di Puskesmas Ubung Lombok Tengah. Skripsi. Mataram: Poltekkes Kemenkes Mataram. 1(1), 38-49.

Supa, I., Zakaria, Z., Maskon, O., Aminuddin, A., Anita, N., \& Mohd, M. (2013). Effects of Swedish Massage Therapy on Blood Pressure, Heart Rate, and Inflammatory Markers in Hypertensive Women. Hindawi Publishing Corporation: Medical Department, Cardiology Unit. Universiti Kebangsaan Malaysia Medical Centre. 2

Taufik Septiawan, Iman Permana, F. A. Y. (2018). Hypertension, Pengaruh Latihan Slow Deep Breathing Terhadap Nilai Tekanan Darah Pada Pasien Hipertensi The Effect of Slow Deep Breathing Exercise on Blood Pressure Value in Patient With. Tesis. Yogyakarta: Universitas Muhammadiyah Yogyakarta. 111-118.

Triyanto, Endang. 2014. Pelayanan Keperawatan bagi Penderita Hipertensi Secara Terpadu. Buku. Yogyakarta: Graha IImu.

Wahyuningsih, A., \& Astarini, K. (2018). Metode Massage Terhadap Tekanan Darah pada Penderita Hipertensi: a Literatur Review. Penelitian Keperawatan. Tesis. Yogyakarta: Universitas Muhammadiyah Yogyakarta. 4(2).

World Health Organization. (2013). High Blood Pressure: The Silent Killer Stay healthy: Check your blood pressure Do I have high blood pressure? How can high blood pressure be prevented?. Jean-Alain Le Borgne, WHO: World Health Organization.

Wiharja, W., Pranata, R., Fatah, A., Kurniadi, I. C., Deka, H., \& Damay, V. A. (2016). Acute Effect of Slow Deep Breathing Maneuver on Patient with Essential Hypertension Stage 1 and 2. Departement of Cardiovascular, Siloam Hospital Lippo Village: Jurnal Kardiologi Indonesia. 37(2), 75-80.

Wiwit, D. I., Lina, P., Aminah. S. O. (2018). Efektivitas Swedish Massage Therapy (SMT) pada Ibu Lansia Sebagai Upaya Penatalaksanaan Hipertensi di Posyandu Lansia. Skripsi. Cilacap: Akademi Kebidanan Graha Mandiri Cilacap. 138-148.

Yanti, N. P. E. D., Mahardika, I. A. L., \& Prapti, N. K. G. (2016). Pengaruh Slow Deep Breathing Terhadap Tekanan Darah pada Penderita Hipertensi Di Wilayah Kerja Puskesmas I Denpasar Timur. Minimally Invasive Therapy and Allied Technologies. Universitas Udayana: Jurnal Keperawatan dan Pemikiran IImiah. 2(4), 1-10.

Yulianti, I. (2019). Pengaruh pemberian Pisang Ambon terhadap Tekanan Darah pada Lansia Penderita Hipertensi. STIKES Bina Sehat PPNI Mojokerto: Jurnal Ners Dan Kebidanan (Journal of Ners and Midwifery), 6(1), 070-076. 